\title{
Prediction of systemic exposure to cyclosporine in Japanese pediatric patients
}

\author{
Toshiyuki Sakaeda $\cdot$ Kazumoto Iijima $\cdot$ Kandai Nozu $\cdot$ Tsutomu Nakamura $\cdot$ \\ Yuka Moriya $\cdot$ Mika Nishikawa $\cdot$ Atsushi Wada Noboru Okamura · \\ Masafumi Matsuo $\cdot$ Katsuhiko Okumura
}

Received: 16 May 2006/ Accepted: 3 August 2006/Published online: 14 September 2006

(C) The Japan Society of Human Genetics and Springer 2006

\begin{abstract}
The monitoring of the blood concentration at $2 \mathrm{~h}\left(\mathrm{C}_{2}\right)$ after the oral administration of a cyclosporine (CsA) microemulsion was reconfirmed to be useful for the prediction of systemic exposure, the area under the blood concentration-time curve from 0 to $4 \mathrm{~h}\left(\mathrm{AUC}_{0-4}\right)$, in a group of Japanese patients, consisting of 33 children aged 5-15 years and 19 young adults aged 16-27 years, with a greater correlation for $\mathrm{C}_{2}(r=0.927)$ than the trough concentration $(r=0.488)$. The dose-normalized $\mathrm{AUC}_{0-4}$ was independent of gender or indications for CsA, while it depended on body size, i.e., the age $(P=0.065)$ and total body weight $(P=0.026) . M D R 1 \mathrm{C} 3435 \mathrm{~T}$ had a weak, but insignificant effect $(P=0.072)$; it was about $22-31 \%$ lower in the patients with $\mathrm{TT}^{3435}$. Coadministration of a steroid and further treatment with nifedipine had a more intensive effect $(P=0.018)$; co-administration resulted in a $51 \%$ increase in the dose-normalized $\mathrm{AUC}_{0-4}$. A strong effect was also observed for the serum total cholesterol level
\end{abstract}

T. Sakaeda $(\bowtie) \cdot$ T. Nakamura $\cdot$ Y. Moriya $\cdot$

M. Nishikawa $\cdot$ A. Wada $\cdot$ K. Okumura

Department of Hospital Pharmacy,

School of Medicine, Kobe University, 7-5-2, Kusunoki-cho,

Chuo-ku, Kobe 650-0017, Japan

e-mail: sakaedat@med.kobe-u.ac.jp

K. Iijima $\cdot$ K. Nozu $\cdot$ M. Matsuo

Department of Pediatrics,

Kobe University Graduate School of Medicine,

7-5-1, Kusunoki-cho, Chuo-ku, Kobe 650-0017, Japan

N. Okamura $\cdot$ K. Okumura

Department of Clinical Evaluation of Pharmacotherapy,

Kobe University Graduate School of Medicine, 1-5-6,

Minatojima-minamimachi, Chuo-ku, Kobe 650-0047, Japan
$(P=0.001)$. Collectively, the discrepancies in the results on MDR1 C3435T among investigators might be due to variability in the age/total body weight, coadministration drugs or serum lipid level.

Keywords Cyclosporine $(\mathrm{CsA}) \cdot \mathrm{C}_{2}$ monitoring · Pediatric patients $\cdot$ MDR1

\section{Introduction}

Cyclosporine (INN, ciclosporin; CsA) has been an essential drug for immunosuppressive therapy for more than 20 years, but it is only recently that a patient management strategy to ensure greater safety and efficacy has come to be proposed (Fahr 1993; Levy 2001; Wong 2001; Cole et al. 2002; Levy et al. 2002; Monaco 2002; Nashan et al. 2002; Citterio 2004). This is primarily due to the development of the oral formulation of a CsA microemulsion, Neoral, and the accumulation of clinical studies on CsA pharmacokinetics and clinical outcomes in adult renal and liver transplant recipients. CsA is a drug with a low therapeutic index, requiring individualization and continuous adjustment of the dosage regimen based on therapeutic drug monitoring. Conventional monitoring of the trough level $\left(\mathrm{C}_{0}\right)$ of the blood concentration has been used to predict systemic exposure to CsA, usually assessed based on the area under the blood concentration-time curve (AUC), after oral administration. Recently, it has become evident that the AUC is indeed an appropriate index of the immunosuppressive effect and toxicity of CsA; however, it is little reflected by $\mathrm{C}_{0}$. Considerable intra- and inter-patient variability in exposure to CsA is found during the initial period 
after oral administration, suggesting the monitoring of AUC during the initial $4 \mathrm{~h}\left(\mathrm{AUC}_{0-4}\right)$ to be useful for patient management, and later, the monitoring of the blood concentration at $2 \mathrm{~h}$ post-dose $\left(\mathrm{C}_{2}\right)$ as a surrogate marker based on clinical results showing $\mathrm{AUC}_{0-4}$ to be correlated with $\mathrm{C}_{2}$. In 2002, the Consensus on Neoral $\mathrm{C}_{2}$ : Expert Review in Transplantation (CONCERT) conference was convened to undertake a multidisciplinary review of pharmacokinetic and clinical data on CsA microemulsions, and an international consensus on a patient management strategy with the oral administration of a CsA microemulsion and $\mathrm{C}_{2}$ monitoring was achieved (Cole et al. 2002; Levy et al. 2002; Monaco 2002; Nashan et al. 2002).

This strategy has resulted from over 20 years of investigation; however, most of the data are on adult patients, and relatively little information is available on pediatric patients. The applicability of $\mathrm{C}_{2}$ monitoring to pediatric patients is still being debated given the age-specific pharmacokinetic properties of CsA (del Mar Fernández de Gatta et al. 2002; Dunn 2003). Thus, the present study was conducted (1) to reconfirm the usefulness of $\mathrm{C}_{2}$ monitoring to predict the systemic exposure to CsA in pediatric patients and (2) to identify the factors affecting the systemic exposure to CsA. The factors analyzed herein included pre-existing conditions, such as the gender, age, total body weight, indications for CsA, and MDR1 genotype of the patients as well as day-to-day variable conditions, such as the co-administration of a steroid and further treatment with nifedipine and the results of clinical laboratory tests on the day of investigation. MDR1 encodes the multi-drug-resistant transporter MDR1/P-glycoprotein (Sakaeda et al. 2003, 2004, 2005; Okamura et al. 2004). CsA is a typical substrate of MDR1, and MDR1 in the villus epithelium of the small intestine is considered to play a role in limiting the intestinal absorption of CsA (Lown et al. 1997; Sakaeda et al. 2003, 2004, 2005; Okamura et al. 2004).

\section{Materials and methods}

\section{Patients}

Fifty-two Japanese patients, 32 boys and 20 girls, visiting the Department of Pediatrics, Kobe University Hospital, Kobe, Japan, were enrolled in this study. The age $( \pm \mathrm{SD})$ was $14.1 \pm 5.2$ years, and the patients were classified into two subpopulations: 33 children aged 5-15 years and 19 young adults aged 16-27 years. Total body weight $( \pm \mathrm{SD})$ was
$42.5 \pm 12.9 \mathrm{~kg} \quad(19.0-74.5 \mathrm{~kg})$. The patients were maintained in a stable condition by a twice-daily oral dosing of the CsA microemulsion (Neoral; Novartis Pharma, USA), and the indications for CsA included post-renal transplantation $(n=19)$, nephrotic syndrome $(n=25)$ and systemic lupus erythematosus (SLE; $n=8)$. The maintenance dose $( \pm \mathrm{SD})$ was $3.36 \pm 0.94 \mathrm{mg} / \mathrm{kg} / \mathrm{day}(1.34-6.00 \mathrm{mg} / \mathrm{kg} / \mathrm{day})$. A steroid, i.e., prednisolone or methylprednisolone, was coadministered to 39 of 52 patients, and nifedipine was additionally administered to 11 of 39 patients, and their maintenance dose $( \pm \mathrm{SD})$ was $0.63 \pm 0.57 \mathrm{mg} / \mathrm{kg} /$ day $\quad(0.11-1.75 \mathrm{mg} / \mathrm{kg} / \mathrm{day}), \quad 0.22 \pm 0.12 \mathrm{mg} / \mathrm{kg} /$ day $(0.08-0.60 \mathrm{mg} / \mathrm{kg} / \mathrm{day})$ and $0.70 \pm 0.33 \mathrm{mg} / \mathrm{kg} / \mathrm{day}$ $(0.40-1.33 \mathrm{mg} / \mathrm{kg} / \mathrm{day})$, respectively. No serious renal impairment was confirmed by periodic pathohistological examinations. The aims of the study were fully explained to every subject and/or their parents, and written informed consent was obtained. The protocol was approved by the Institutional Review Board of Kobe University Hospital, Kobe University, Japan.

Assessment of systemic exposure to CsA after oral administration, and its predictability by $\mathrm{C}_{2}$ monitoring

After confirmation that the patient was in a steady state based on continuous $\mathrm{C}_{0}$ monitoring, the pharmacokinetic profile was evaluated. On the day of the investigation, whole blood samples were obtained from the peripheral vein in EDTA-containing polyethylene tubes prior to and at $1,2,3$ and $4 \mathrm{~h}$ after oral administration to assess $\mathrm{C}_{0}, \mathrm{C}_{1}, \mathrm{C}_{2}, \mathrm{C}_{3}$, and $\mathrm{C}_{4}$, respectively. The samples were stored at $-20^{\circ} \mathrm{C}$ until the analysis. CsA concentrations were measured by monoclonal fluorescence polarization immunoassay using the TDx operation system (Abbott Laboratory, North Chicago, IL) according to the manufacturer's manual, and the measurement method was validated in terms of precision and accuracy, and also day-today variation. The systemic exposure to CsA was assessed using $\mathrm{AUC}_{0-4}$, which was calculated by the linear trapezoidal rule using the pharmacokinetic software package WinNonlin Ver. 4.0 (Pharsight Co., Mountain View, CA). The correlation between $\mathrm{AUC}_{0-4}$ and either $\mathrm{C}_{0}, \mathrm{C}_{1}, \mathrm{C}_{2}, \mathrm{C}_{3}$ or $\mathrm{C}_{4}$ was tested using Pearson's correlation test, and $P$ values of less than 0.05 were considered significant. The correlation was also evaluated after stratification based on the gender, age, indications for CsA, and MDR1 genotypes of the patients, as well as co-administration of a steroid and further treatment with nifedipine. 
Assessment of factors affecting systemic exposure to CsA

The analysis was conducted after exclusion of the data on four slow absorbers, defined herein as patients with a $t_{\max }$, time to maximum blood concentration $\left(C_{\max }\right)$, of $4 \mathrm{~h}$ or more (see Fig. 1), since the values of $\mathrm{AUC}_{0-4}$ were expected to be underestimated. There was a considerable variation in the maintenance dose of CsA; thus, the analysis was performed after dose-normalization of $\mathrm{AUC}_{0-4}$ at a dose of $3 \mathrm{mg} / \mathrm{kg} / \mathrm{day}$ according to the equation: $\mathrm{AUC}_{0-4, \text { corr. }}=\mathrm{AUC}_{0-4} \times[3(\mathrm{mg} / \mathrm{kg} /$ day $) /$ dose $(\mathrm{mg} / \mathrm{kg} /$ day $)]$. The factors analyzed in terms of association with $\mathrm{AUC}_{0-4, \text { corr. }}$ included gender (31 males and 17 females), age (29 children and 19 young adults), total body weight $(20.0-74.5 \mathrm{~kg})$, indications for CsA (16 post-renal transplantations, 24 nephrotic syndromes, and $8 \mathrm{SLE}$ ), and MDR1 genotype. The effects of the co-administration of a steroid and further treatment with nifedipine (12 controls, 25 a steroid, and 11 both a steroid and nifedipine), and serum alanine aminotransferase (ALT, 12-33 IU/l), serum aspartate aminotransferase (AST, 5-80 IU/l), serum albumin level (Alb, 2.5-4.6 g/dl), serum creatinine level (Scr, 0.24-2.17 mg/dl), hematocrit (Ht, 26.0-45.5\%) and serum total cholesterol level (T-Chol, 120-588 mg/ dl) on the day of investigation were also evaluated. The MDR1 genetic polymorphisms examined herein were T-129C (36 TT, 12 CT, and 0 CC), C1236T (5 CC, 22 CT, and 21 TT), G2677A,T (10 GG, 7 GA, 16 GT, 0 AA, 7 AT, and 8 TT) and C3435T (13 CC, 27 CT, and 8 TT). The comparisons of $\mathrm{AUC}_{0-4, \text { corr. }}$ between and among groups were performed using the unpaired Student's $t$-test and ANOVA/Tukey-Kramer test, respectively, provided that the variances of the groups

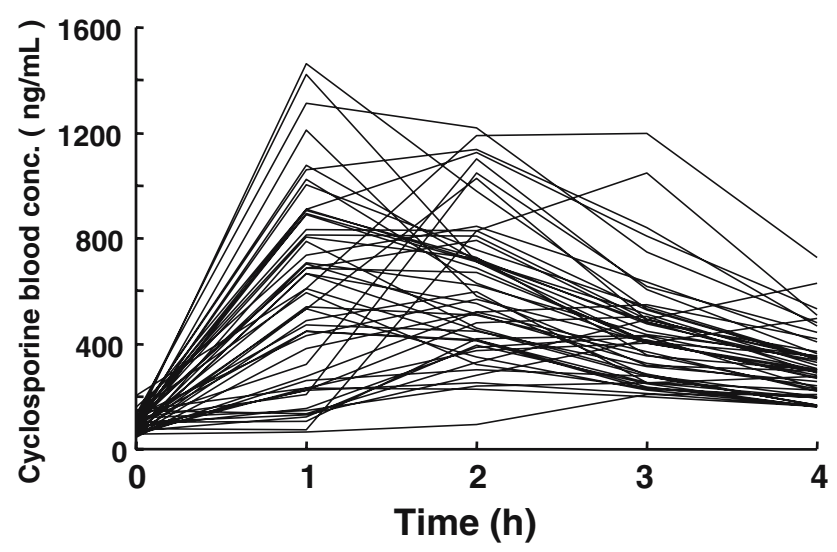

Fig. 1 Blood concentration-time profiles after oral administration of the cyclosporine microemulsion (Neoral) in 52 Japanese patients. The subjects consisted of 29 children and 19 young adults. There were four slow absorbers $(7.7 \%)$ were similar as assessed by the $F$ test. If this was not the case, a Mann-Whitney $U$ test or a Kruskal-Wallis analysis/Mann-Whitney $U$ test was applied, respectively. $P$ values of less than 0.05 (two-tailed) were considered significant. For age, total body weight and the results of clinical laboratory tests, dependencies were analyzed using Pearson's correlation test.

\section{MDR1 T-129C, C1236T, G2677A,T and C3435T genotyping}

Genomic DNA was extracted from $0.5 \mathrm{ml}$ of whole blood using a DNA extractor WB Kit (Wako Pure Chemical Industries Ltd., Osaka, Japan) as described previously (Sakaeda et al. 2001; Nakamura et al. 2002; Horinouchi et al. 2002; Morita et al. 2003). The genotypes of T-129C, G2677A,T and C3435T of the MDR1 gene were determined by polymerase chain reactionrestriction fragment length polymorphism (PCRRFLP) analysis as described before (Sakaeda et al. 2001; Nakamura et al. 2002; Horinouchi et al. 2002; Morita et al. 2003) and confirmed by direct sequencing. Herein, C1236T was also determined by direct sequencing according to the report by Kim et al. (2001).

\section{Results}

Systemic exposure to CsA after oral administration, and its prediction by $\mathrm{C}_{2}$ monitoring

Figure 1 shows the blood concentration-time profiles of CsA up to $4 \mathrm{~h}$ after the oral administration of the CsA microemulsion in 52 Japanese patients. There was considerable variation in the blood concentration-time profiles, and the $t_{\max }$ was $1 \mathrm{~h}(n=28) ; 2 \mathrm{~h}(n=13), 3 \mathrm{~h}$ $(n=7)$ and $4 \mathrm{~h}(n=4)$. The ratio of slow absorbers, defined as a patient with a $t_{\max }$ of $4 \mathrm{~h}$ or more, was $4 / 52$ $(7.7 \%)$. Their maintenance dose $( \pm \mathrm{SD})$ was $3.74 \pm 0.75 \mathrm{mg} / \mathrm{kg} / \mathrm{day}$, which was not different from that in other patients. The slow absorbers consisted of one boy and three girls. At an average age $( \pm \mathrm{SD})$ of $11.5 \pm 4.0$ years, they were slightly younger than the others. Total body weight $( \pm \mathrm{SD})$ was $32.3 \pm 11.8 \mathrm{~kg}$, also down slightly, but the slow absorbers were not characterized by the other factors assessed herein, including indications for CsA, $M D R 1$ genotypes at four positions, co-administered drugs and the values of ALT, AST, Alb, T-Chol, Scr and Ht.

Figure 2 shows the relationship between $\mathrm{AUC}_{0-4}$ and $\mathrm{C}_{0}$ or $\mathrm{C}_{2}$ in 52 Japanese patients. A statistically significant correlation was observed for both, but the 

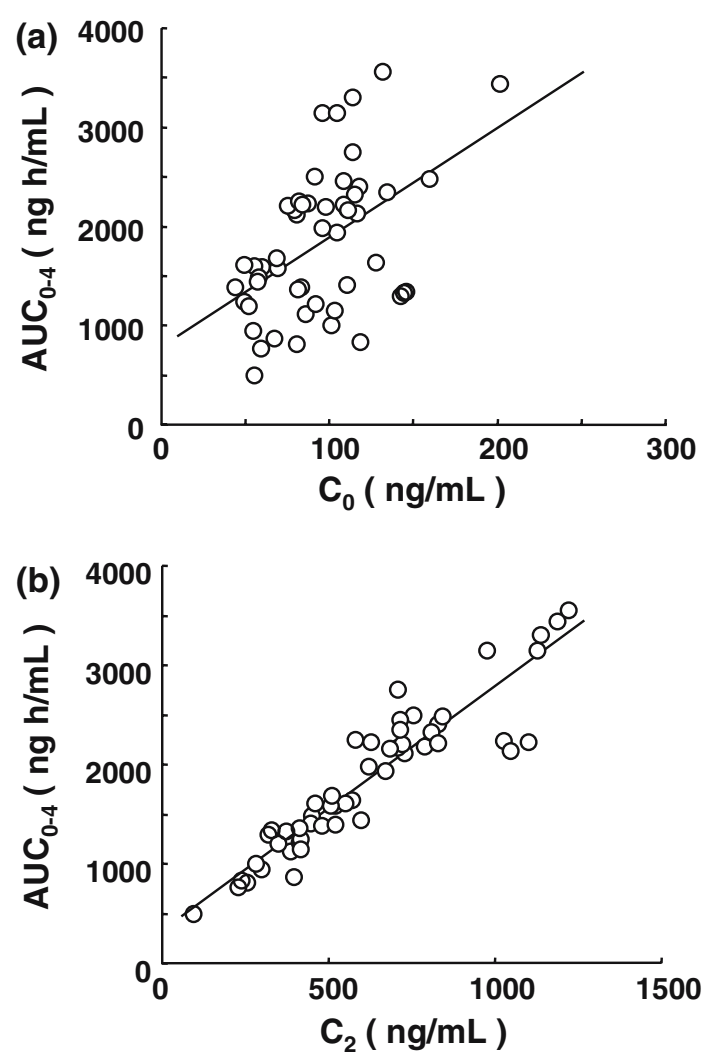

Fig. 2 Relationship between $\mathrm{AUC}_{0-4}$ and $\mathrm{C}_{0}(\mathbf{a})$ or $\mathrm{C}_{2}$ (b) in 52 Japanese patients. The subjects consisted of 29 children and 19 young adults. A higher correlation coefficient was obtained for $\mathrm{C}_{2} \quad(r=0.927, P<0.05)$ than $\mathrm{C}_{0}(r=0.488, P<0.05)$. The exclusion of four slow absorbers resulted in a higher correlation coefficient for $\mathrm{C}_{0}(r=0.590)$, but not for $\mathrm{C}_{2}(r=0.917)$

coefficient was higher for $\mathrm{C}_{2}(r=0.927)$ than $\mathrm{C}_{0}$ $(r=0.488)$. Exclusion of the four slow absorbers resulted in a higher correlation coefficient for $\mathrm{C}_{0}$ $(r=0.590)$, but not for $\mathrm{C}_{2}(r=0.917)$. Table 1 lists the association of age with the coefficients of the correlation between $\mathrm{AUC}_{0-4}$ and $\mathrm{C}_{0}$ to $\mathrm{C}_{4}$, where the patients were classified into two subpopulations of 33 children and 19 young adults. $\mathrm{AUC}_{0-4}$ values were better correlated with the values of $\mathrm{C}_{0}$ to $\mathrm{C}_{4}$ for children than young adults, but the best surrogate marker was $\mathrm{C}_{2}$ for both ( $r=0.945$ and 0.854 , respectively). Interestingly, $\mathrm{C}_{0}$ was correlated with $\mathrm{AUC}_{0-4}$ in children $(r=0.551)$, whereas no correlation was found for young adults $(r=0.237)$. The correlation between $\mathrm{AUC}_{0-4}$ and $\mathrm{C}_{2}$ was independent of gender, indications for CsA, MDR1 genotypes, and co-administration of a steroid and further treatment with nifedipine.

Factors affecting systemic exposure to CsA

Table 2 summarizes the results of statistical analyses for the association of various factors with $\mathrm{AUC}_{0-4, \mathrm{corr}}$. The average values of $\mathrm{AUC}_{0-4, \text { corr. }}$ in each group are listed in Table 3. No effect of gender on $\mathrm{AUC}_{0-4 \text {,corr. }}$ was observed $(P=0.508)$. The values of $\mathrm{AUC}_{0-4, \text { corr. }}$ tended to be lower in younger patients, although the analysis was not sufficiently powered to reach statistical significance $(P=0.065)$, and the value for children, $1,711 \pm 718 \mathrm{ng} \mathrm{h} / \mathrm{ml}$, was about $10 \%$ less than that for young adults, $1,915 \pm 552 \mathrm{ng} \mathrm{h} / \mathrm{ml}$. The $\mathrm{AUC}_{0-4 \text {,corr. }}$. depended on total body weight $(P=0.026)$, with heavier patients having greater values, but was independent of indications for CsA $(P=0.948)$. Among the four genotypes of $M D R 1, \mathrm{C} 3435 \mathrm{~T}$ had the greatest effect on $\mathrm{AUC}_{0-4, \text { corr. }}$, but the difference was not statistically significant $(P=0.072)$. The average values were $1,738 \pm 590,1,948 \pm 678$ and $1,351 \pm 536 \mathrm{ng} \mathrm{h} / \mathrm{ml}$ for the patients with $\mathrm{CC}^{3435}, \mathrm{CT}^{3435}$ and $\mathrm{TT}^{3435}$, respectively; they were $22-31 \%$ lower in those with $\mathrm{TT}^{3435}$ than the others. Comparisons among the patients with $\mathrm{GG}^{2677} / \mathrm{CC}^{3435}, \mathrm{GT}^{2677} / \mathrm{CT}^{3435}$ and $\mathrm{TT}^{2677} /$ $\mathrm{TT}^{3435}$ revealed no advantage over the stratification based on only C3435T (data not shown).

There was an intensive effect of the co-administration of a steroid and further treatment with nifedipine $(P=0.018)$. The co-administration with a steroid resulted in about a 1.2-fold increase in $\mathrm{AUC}_{0-4, \text { corr. }}$ to $1,758 \pm 537 \mathrm{ng} \mathrm{h} / \mathrm{ml}$ from that in the patients without a steroid or nifedipine treatment $(1,468 \pm 743 \mathrm{ng} \mathrm{h} / \mathrm{ml})$, and further treatment with nifedipine resulted in a $51 \%$ increase, to $2,221 \pm 639 \mathrm{ng} \mathrm{h} / \mathrm{ml}$. The values of AST, Alb, Scr and Ht had no effect on $\mathrm{AUC}_{0-4, \text { corr., }}$ while T-Chol had a substantial effect $(P=0.001)$, with higher values associated with a higher $\mathrm{AUC}_{0-4 \text {,corr }}$. ALT values also gave a significant correlation

Table 1 Coefficients of the correlation $(r)$ between $\mathrm{AUC}_{0-4}$ and $\mathrm{C}_{0}-\mathrm{C}_{4}$ of cyclosporine in 52 Japanese patients

\begin{tabular}{llllllll}
\hline & Age & $N$ & $\mathrm{C}_{0}$ & $\mathrm{C}_{1}$ & $\mathrm{C}_{2}$ & $\mathrm{C}_{3}$ & $\mathrm{C}_{4}$ \\
\hline Children & $5-15$ & $33(29)$ & $0.551(0.718)^{*}$ & $0.818(0.793)^{*}$ & $0.945(0.937)^{*}$ & $0.812(0.809)^{*}$ & $0.641(0.816) *$ \\
Young adults & $16-27$ & 19 & 0.237 & $0.584^{*}$ & $0.854^{*}$ & $0.638^{*}$ & $0.727^{*}$ \\
Total & & $52(48)$ & $0.488(0.590)^{*}$ & $0.766(0.737)^{*}$ & $0.927(0.917)^{*}$ & $0.755(0.754)^{*}$ & $0.640(0.791)^{*}$ \\
\hline
\end{tabular}

The patients were classified into two subpopulations; the children were aged 5-15 years, and young adults were aged 16-27 years. Correlation coefficients after the exclusion of four slow absorbers, all belonging to the children's group, are in parentheses

$* P<0.05$ 
Table 2 Association of various factors with systemic exposure to cyclosporine, AUC $\mathrm{A}_{0-4 \text {,corr. }}$ in 48 Japanese patients

\begin{tabular}{|c|c|c|c|}
\hline & Unpaired Student's $t$ test & ANOVA/Tukey-Kramer test & Pearson's correlation test \\
\hline Gender & $P=0.508$ & - & - \\
\hline $\operatorname{Age}^{\mathrm{a}}$ & $P=0.300$ & - & $r=0.268, P=0.065$ \\
\hline Total body weight & - & - & $r=0.321, P=0.026$ \\
\hline Indications for CsA & - & $P=0.948$ & - \\
\hline \multicolumn{4}{|l|}{ MDR1 } \\
\hline $\mathrm{T}-129 \mathrm{C}^{\mathrm{b}}$ & $P=0.414$ & - & - \\
\hline $\mathrm{C} 1236 \mathrm{~T}$ & - & $P=0.478$ & - \\
\hline $\mathrm{G} 2677 \mathrm{~A}, \mathrm{~T}^{\mathrm{c}}$ & - & $P=0.150$ & - \\
\hline $\mathrm{C} 3435 \mathrm{~T}$ & - & $P=0.072$ & - \\
\hline Co-administration $^{\mathrm{d}}$ & - & $P=0.018$ & - \\
\hline ALT & - & - & $r=-0.386, P=0.007$ \\
\hline AST & - & - & $r=0.006, P=0.966$ \\
\hline Alb & - & - & $r=-0.221, P=0.131$ \\
\hline Scr & - & - & $r=0.183, P=0.214$ \\
\hline $\mathrm{Ht}$ & - & - & $r=-0.012, P=0.935$ \\
\hline T-chol & - & - & $r=0.458, P=0.001$ \\
\hline
\end{tabular}

The analysis was performed after exclusion of the data on four slow absorbers, and dose-normalization of $\mathrm{AUC}_{0-4}$ at a dose of $3 \mathrm{mg} / \mathrm{kg} /$ day according to the equation: $\mathrm{AUC}_{0-4, \text { corr. }}=\mathrm{AUC}_{0-4} \times[3(\mathrm{mg} / \mathrm{kg} / \mathrm{day}) / \mathrm{dose}(\mathrm{mg} / \mathrm{kg} / \mathrm{day})]$

a The effect of age was analyzed after the stratification of patients into two subpopulations, children aged 5-15 years and young adults aged 16-27 years, or using Pearson's correlation test

b There was no patient with $\mathrm{CC}^{-129}$, and the data on $\mathrm{TT}^{-129}$ and $\mathrm{TC}^{-129}$ were compared

c The effect of MDR1 G2677A,T was analyzed among the patients with GG, GA + GT and AA + AT + TT

d A comparison was performed among the patients treated without either a steroid or nifedipine, with a steroid, and with both a steroid and nifedipine. All patients treated with nifedipine were administered a steroid

Table 3 Effects of age, MDR1 C3435T and co-administration of a steroid and further treatment with nifedipine on systemic exposure to cyclosporine, $\mathrm{AUC}_{0-4 \text {,corr. }}$ in 48 Japanese patients

\begin{tabular}{|c|c|c|c|c|}
\hline & $N$ & Dose (mg/kg/day) & $\mathrm{AUC}_{0-4}(\mathrm{ng} \mathrm{h} / \mathrm{ml})$ & $\mathrm{AUC}_{0-4, \text { corr. }}(\mathrm{ng} \mathrm{h} / \mathrm{ml})$ \\
\hline Total & 48 & $3.33 \pm 0.95$ & $1,909 \pm 708$ & $1,792 \pm 659$ \\
\hline \multicolumn{5}{|l|}{ Age } \\
\hline Children (5-15 years) & 29 & $3.45 \pm 1.04$ & $1,894 \pm 820$ & $1,711 \pm 718$ \\
\hline Young adults (16-27 years) & 19 & $3.14 \pm 0.80$ & $1,932 \pm 513$ & $1,915 \pm 552$ \\
\hline \multicolumn{5}{|l|}{ MDRI C3435T } \\
\hline $\mathrm{CC}$ & 13 & $3.22 \pm 1.10$ & $1,831 \pm 818$ & $1,738 \pm 590$ \\
\hline CT & 27 & $3.35 \pm 1.01$ & $2,060 \pm 649$ & $1,948 \pm 678$ \\
\hline $\mathrm{TT}$ & 8 & $3.42 \pm 0.48$ & $1,526 \pm 623$ & $1,351 \pm 536$ \\
\hline \multicolumn{5}{|l|}{ Co-administration } \\
\hline None & 12 & $3.02 \pm 0.82$ & $1,349 \pm 515$ & $1,468 \pm 743$ \\
\hline Steroid & 25 & $3.47 \pm 0.89$ & $1,979 \pm 587$ & $1,758 \pm 537$ \\
\hline Steroid + nifedipine & 11 & $3.33 \pm 1.22$ & $2,367 \pm 787$ & $2,221 \pm 639$ \\
\hline
\end{tabular}

The values are the mean \pm SD. The analysis was performed after exclusion of the data on four slow absorbers, and dose-normalization of $\mathrm{AUC}_{0-4}$ at a dose of $3 \mathrm{mg} / \mathrm{kg} /$ day according to the equation: $\mathrm{AUC}_{0-4, \text { corr. }}=\mathrm{AUC}_{0-4} \times[3(\mathrm{mg} / \mathrm{kg} / \mathrm{day}) / \mathrm{dose}(\mathrm{mg} / \mathrm{kg} / \mathrm{day})]$. The factors analyzed in terms of association with $\mathrm{AUC}_{0-4, \text { corr. }}$ included gender, age, total body weight, indications for CsA and MDR1 T-129C, C1236T, G2677A,T and C3435T genotype, as well as co-administration of a steroid and further treatment with nifedipine and the values of ALT (IU/l), AST (IU/l), Alb (g/dl), Ht (\%), Scr (mg/dl) and T-Chol (mg/dl) on the day of the investigation. No factors other than age, MDR1 C3435T and co-administration were demonstrated to have an effect on $\mathrm{AUC}_{0-4 \text {,corr }}$

$(P=0.007)$, although those values were all within its normal range.

\section{Discussion}

The CONCERT conference in 2002 was held to compare conventional $\mathrm{C}_{0}$ monitoring with alternatively proposed $\mathrm{C}_{2}$ monitoring and to reach an agreement on target values of $\mathrm{C}_{2}$ (Cole et al. 2002; Levy et al. 2002; Monaco 2002; Nashan et al. 2002). A range of clinical investigations has confirmed that $\mathrm{C}_{2}$ monitoring with the use of a CsA microemulsion, Neoral, is superior for the prevention of acute rejection in de novo renal and liver transplant recipients without serious detrimental effects on renal function, and also in maintenance 
through the avoidance of unexpected over- or underexposure to CsA. In 2003, a report of MO2ART (monitoring of 2-h absorption in renal transplantation), the first prospective, multicenter trial of $\mathrm{C}_{2}$ monitoring in de novo renal recipients receiving CsA microemulsions, was published, and target values of $\mathrm{C}_{2}$ monitoring were presented (Thervet et al. 2003).

The data with which this conclusion was made are those on adult patients. Since there are two unique features to consider regarding the pharmacokinetics of CsA in pediatric patients, (1) the bioavailability of CsA correlates with age, being lower in younger patients and (2) pediatric patients have a higher rate of metabolism (del Mar Fernández de Gatta et al. 2002; Dunn 2003), the guidelines established in adult patients may not apply to pediatric patients. Here, the age-dependent pharmacokinetics of CsA after the oral administration of a CsA microemulsion was evaluated to reconfirm the usefulness of $\mathrm{C}_{2}$ monitoring in pediatric patients in terms of predictability of systemic exposure to CsA. There were four slow absorbers $(7.7 \%)$, patients with a $t_{\max }$ of $4 \mathrm{~h}$ or more (Fig. 1), for which $\mathrm{C}_{2}$ monitoring would result in an overdose of CsA (Cole et al. 2002; Levy et al. 2002; Monaco 2002; Nashan et al. 2002; Nozu et al. 2005). It is noted that the concentrations were determined up to $4 \mathrm{~h}$ after administration, and these four patients might be low absorbers, not be slow absorbers. All belonged to the children's group, aged 515 years. Although further investigation is needed, the delay of the peak time is expected to be due to immature gastrointestinal function, including defective bile acid secretion, or overexpression of metabolizing enzymes or efflux transporters in the intestine and/or liver. Despite this issue, it has been found that $\mathrm{AUC}_{0-4}$ values were better correlated with the $\mathrm{C}_{0}-\mathrm{C}_{4}$ for the children than young adults aged 16-27 years, but the best surrogate marker was $\mathrm{C}_{2}$ for both groups (Fig. 2; Table 1). In Fig. 2, the data of four slow absorbers were all located in the left-lower part, suggesting the underestimation of $\mathrm{AUC}_{0-4}$, and the data on these patients were excluded in the latter assessment.

This study was conducted also to identify the factors affecting systemic exposure to CsA, and for it, the $\mathrm{AUC}_{0-4}$ values were normalized at a dose of $3 \mathrm{mg} / \mathrm{kg} /$ day as $\mathrm{AUC}_{0-4, \text { corr. }}$ after exclusion of the data on the four slow absorbers. As shown in Tables 2 and 3, the $\mathrm{AUC}_{0-4, \text { corr. }}$ was independent of gender or indications for CsA, but depended on body size, i.e., it tended to be higher in older patients $(P=0.065)$ and in the patients with a higher total body weight $(P=0.026)$. This is explained by age-dependent metabolic ability via the CYP3A family (del Mar Fernández de Gatta et al. 2002; Dunn 2003).
MDR1 T-129C, C1236T, and G2677A,T had no effect on the $\mathrm{AUC}_{0-4, \text { corr. }}$, but $\mathrm{C} 3435 \mathrm{~T}$ had a weak, though insignificant, effect $(P=0.072)$. As the pharmacokinetics of CsA is regulated by MDR1 and the CYP3A family (Lown et al. 1997; del Mar Fernández de Gatta et al. 2002; Kelly and Kahan 2002; Ponticelli 2005), the genetic effects of these proteins are often investigated in terms of the steady-state pharmacokinetics of CsA. Most research has focused on C3435T for $M D R 1$, due to its association with the expression of MDR1 in the tissues (Sakaeda et al. 2003, 2004, 2005; Okamura et al. 2004), and on $C Y P 3 A 4 * 1 B$ or $C Y P 3 A 5^{*} 3$, due to its association with a higher level of CYP3A4 (Amirimani et al. 1999) and a deficiency of protein (Hustert et al. 2001; Kuehl et al. 2001), respectively. The first report was presented by von Ahsen et al. (2001), who indicated that the maintenance dose or dose-adjusted $\mathrm{C}_{0}$ of CsA was independent of either MDR1 C3435T or CYP3A4 genotype in renal transplant recipients. Several other investigators indicated no effect of MDR1 T-129C, C1236T, G2677T or C3435T on the dose-adjusted concentrations of CsA (Mai et al. 2003; Kuzuya et al. 2003; Hesselink et al. 2003; Haufroid et al. 2004). Hesselink et al. (2003) reported no effect of $C Y P 3 A 4^{*} 1 B$ and $C Y P 3 A 5^{*} 1$ on the dose-adjusted $\mathrm{C}_{0}$ of CsA, but Haufroid et al. (2004) suggested that values were higher for $C Y P 3 A 5 * 3 / * 3$ than $* 1 / * 3$. In contrast, Yates et al. (2003) reported that the dose-adjusted concentration of CsA was higher in renal transplant recipients with $\mathrm{CC}^{3435}$ than $\mathrm{CT}^{3435}$ or $\mathrm{TT}^{3435}$. Bonhomme-Faivre et al. (2004) also suggested that the dose-adjusted concentration of CsA was higher, whereas a lower maintenance dose was needed in $\mathrm{T}^{3435}$-allele carriers among liver-transplant recipients. Anglicheau et al. (2004) suggested that dose-adjusted concentrations of CsA were independent of C3435T, but were higher in $\mathrm{T}^{1236}$-allele carriers in renal transplant recipients. As listed above, there are still considerable discrepancies in the results on C3435T, suggesting that MDR1 has no or only slight effects on CsA pharmacokinetics after oral administration (Sakaeda et al. 2003, 2004, 2005; Okamura et al. 2004). In this study, several factors proved to have a stronger effect on CsA pharmacokinetics than MDR1 C3435T genotype, also supporting the speculation mentioned above.

In this study, it has been elucidated that coadministration of a steroid and further treatment with nifedipine results in a higher $\mathrm{AUC}_{0-4 \text {,corr. }}(P=0.018)$. Orphan nuclear receptors have been recognized as key molecules of drug-induced changes in both metabolism and transporting mechanisms, including CYP3A4 and MDR1 (Pascussi et al. 2003; Staudinger 
et al. 2003; Wang and LeCluyse 2003). Co-administration of a steroid is expected to reduce the systemic exposure to CsA, but it was not supported in this study (Tables 2, 3). The maintenance dose of prednisolone or methylprednisolone was $0.63 \pm 0.57$ and $0.22 \pm 0.12 \mathrm{mg} / \mathrm{kg} / \mathrm{day}$, respectively, and these concentrations might be insufficient for induction of CYP3A4 or MDR1 to give a decrease of systemic exposure to CsA. Nifedipine is well known to be a typical substrate for CYP3A4 (Galetin et al. 2003), but CsA pharmacokinetics is not affected to a clinically significant extent in adult patients (Legault et al. 1993; Crocker et al. 1994). In this study, co-administration of nifedipine resulted in an increase of CsA exposure, and this is specific for pediatric patients (Crocker et al. 1994). The values are higher for patients with a higher T-Chol $(P=0.001)$, and this can be explained simply by the lipophilicity of CsA resulting in condensation in the lipid components in circulating blood, as confirmed by animal experiments (Nakamura et al. 2001). Statistically significant correlation $(P=0.007)$ was also detected for ALT among the results of clinical laboratory tests, but the values of ALT were all within its normal range of our hospital of 8-34 IU/1, suggesting no conclusive information on the association of hepatic hunction with CsA systemic exposure. As shown in Tables 2 and 3, these effects were greater than those of MDR1 genotype, and therefore the discrepancies in the results on C3435T among the investigators might be, in part, due to variability in age/total body weight, type of co-administered drug or lipid status of the patients.

Multivariate analysis was performed to obtain a regression function to estimate the $\mathrm{AUC}_{0-4}$ value and/ or the optimized dose to give a constant $\mathrm{AUC}_{0-4}$. The inclusion of concentration data as variants gave a higher predictability, but it was impossible to elucidate the relationship with the factors affecting it. In contrast, their exclusion resulted in a larger coefficient of variation for each of the parameters. These results strongly suggested extensively large intra- and interindividual variation in CsA pharmacokinetics, being consistent with difficulties in model establishment for population pharmacokinetics.

In summary, $\mathrm{C}_{2}$ monitoring was re-proved to be useful to predict systemic exposure to CsA, $\mathrm{AUC}_{0-4}$ even in pediatric patients. The dose-normalized $\mathrm{AUC}_{0-4}$ was independent of gender or indications for CsA, while it depended on body size, i.e., age and total body weight. MDR1 C3435T, but not T-129C, C1236T or G2677A,T, had a weak, but insignificant, effect, i.e., it was about $22-31 \%$ lower in the patients with TT $^{3435}$ than the others. Co-administration of a steroid and further treatment with nifedipine had a more intensive effect, i.e., co-administration resulted in a $51 \%$ increase in the dose-normalized $\mathrm{AUC}_{0-4}$. A strong effect was observed for the value of T-Chol, but not AST, Alb, Scr or Ht. The discrepancies in the results on MDR1 C3435T among investigators might be due to variability in these factors.

Acknowledgments The present study was supported by the Japan Research Foundation for Clinical Pharmacology, Japan, and the YOKOYAMA Foundation for Clinical Pharmacology, Japan.

\section{References}

Amirimani B, Walker AH, Weber BL, Rebbeck TR (1999) Response: re: modification of clinical presentation of prostate tumors by a novel genetic variant in CYP3A4. J Natl Cancer Inst 91:1588-1590

Anglicheau D, Thervet E, Etienne I, Hurault De Ligny B, Le Meur Y, Touchard G, Buchler M, Laurent-Puig P, Tregouet D, Beaune P, Daly A, Legendre C, Marquet P (2004) CYP3A5 and MDR1 genetic polymorphisms and cyclosporine pharmacokinetics after renal transplantation. Clin Pharmacol Ther 75:422-433

Bonhomme-Faivre L, Devocelle A, Saliba F, Chatled S, Maccario J, Farinotti R, Picard V (2004) MDR-1 C3435T polymorphism influences cyclosporine a dose requirement in liver-transplant recipients. Transplantation 78:21-25

Citterio F (2004) Evolution of the therapeutic drug monitoring of cyclosporine. Transplant Proc 36:420S-425S

Cole E, Midtvedt K, Johnston A, Pattison J, O'Grady C (2002) Recommendations for the implementation of Neoral $\mathrm{C}_{2}$ monitoring in clinical practice. Transplantation 73:S19-S22

Crocker JF, Renton KW, LeVatte TL, McLellan DH (1994) The interaction of the calcium channel blockers verapamil and nifedipine with cyclosporin $\mathrm{A}$ in pediatric renal transplant patients. Pediatr Nephrol 8:408-411

del Mar Fernández De Gatta M, Santos-Buelga D, DominguezGil A, Garcia MJ (2002) Immunosuppressive therapy for paediatric transplant patients: pharmacokinetic considerations. Clin Pharmacokinet 41:115-135

Dunn SP (2003) Neoral monitoring 2 hours post-dose and the pediatric transplant patient. Pediatr Transplant 7:25-30

Fahr A (1993) Cyclosporin clinical pharmacokinetics. Clin Pharmacokinet 24:472-495

Galetin A, Clarke SE, Houston JB (2003) Multisite kinetic analysis of interactions between prototypical CYP3A4 subgroup substrates: midazolam, testosterone, and nifedipine. Drug Metab Dispos 31:1108-1116

Haufroid V, Mourad M, van Kerckhove V, Wawrzyniak J, De Meyer M, Eddour DC, Malaise J, Lison D, Squifflet JP, Wallemacq P (2004) The effect of CYP3A5 and MDR1 (ABCB1) polymorphisms on cyclosporine and tacrolimus dose requirements and trough blood levels in stable renal transplant patients. Pharmacogenetics 14:147-154

Hesselink DA, van Schaik RH, van der Heiden IP, van der Werf M, Gregoor PJ, Lindemans J, Weimar W, van Gelder T 2003 Genetic polymorphisms of the CYP3A4, CYP3A5, and MDR-1 genes and pharmacokinetics of the calcineurin inhibitors cyclosporine and tacrolimus. Clin Pharmacol Ther $74: 245-254$ 
Horinouchi M, Sakaeda T, Nakamura T, Morita Y, Tamura T, Aoyama N, Kasuga M, Okumura K (2002) Significant genetic linkage of MDR1 polymorphisms at positions 3435 and 2677: functional relevance to pharmacokinetics of digoxin. Pharm Res 19:1581-1585

Hustert E, Haberl M, Burk O, Wolbold R, He YQ, Klein K, Nuessler AC, Neuhaus P, Klattig J, Eiselt R, Koch I, Zibat A, Brockmoller J, Halpert JR, Zanger UM, Wojnowski L (2001) The genetic determinants of the CYP3A5 polymorphism. Pharmacogenetics 11:773-779

Kelly P, Kahan BD (2002) Review: metabolism of immunosuppressant drugs. Curr Drug Metab 3:275-287

Kim RB, Leake BF, Choo EF, Dresser GK, Kubba SV, Schwarz UI, Taylor A, Xie HG, McKinsey J, Zhou S, Lan LB, Schuetz JD, Schuetz EG, Wilkinson GR (2001) Identification of functionally variant MDR1 alleles among European Americans and African Americans. Clin Pharmacol Ther 70:189-199

Kuehl P, Zhang J, Lin Y, Lamba J, Assem M, Schuetz J, Watkins PB, Daly A, Wrighton SA, Hall SD, Maurel P, Relling M, Brimer C, Yasuda K, Venkataramanan R, Strom S, Thummel K, Boguski MS, Schuetz E (2001) Sequence diversity in CYP3A promoters and characterization of the genetic basis of polymorphic CYP3A5 expression. Nat Genet 27:383-391

Kuzuya T, Kobayashi T, Moriyama N, Nagasaka T, Yokoyama I, Uchida K, Nakao A, Nabeshima T (2003) Amlodipine, but not MDR1 polymorphisms, alters the pharmacokinetics of cyclosporine A in Japanese kidney transplant recipients. Transplantation 76:865-868

Legault L, Ogilvie RI, Cardella CJ, Leenen FH (1993) Calcium antagonists in heart transplant recipients: effects on cardiac and renal function and cyclosporine pharmacokinetics. Can J Cardiol 9:398-404

Levy GA (2001) $C_{2}$ monitoring strategy for optimizing cyclosporin immunosuppression from the Neoral formation. BioDrugs 15:279-290

Levy G, Thervet E, Lake J, Uchida K; Consensus on Neoral C(2): Expert Review in Transplantation (CONCERT) Group (2002) Patient management by Neoral C2 monitoring: an international consensus statement. Transplantation 73:S12-S18

Lown KS, Mayo RR, Leichtman AB, Hsiao HL, Turgeon DK, Schmiedlin-Ren P, Brown MB, Guo W, Rossi SJ, Benet LZ, Watkins PB (1997) Role of intestinal P-glycoprotein (mdr1) in interpatient variation in the oral bioavailability of cyclosporine. Clin Pharmacol Ther 62:248-260

Mai I, Stormer E, Goldammer M, Johne A, Kruger H, Budde K, Roots I (2003) MDR1 haplotypes do not affect the steadystate pharmacokinetics of cyclosporine in renal transplant patients. J Clin Pharmacol 43:1101-1107

Monaco AP (2002) Editorial comment for supplement entitled "Patient management by Neoral $\mathrm{C}_{2}$ monitoring: from science to practice". Transplantation 73:S1-S2

Morita Y, Sakaeda T, Horinouchi M, Nakamura T, Kuroda K, Miki I, Yoshimura K, Sakai T, Shirasaka D, Tamura T, Aoyama N, Kasuga M, Okumura K (2003) MDR1 genotype-related duodenal absorption rate of digoxin in healthy Japanese subjects. Pharm Res 20:552-556

Nakamura T, Kakumoto M, Sakaeda T, Nagahiro K, Ohmichi R, Yamashita K, Nishiguchi K, Hirai M, Okumura K (2001) Effect of serum triglyceride concentration on the fluctuation of whole blood concentration of cyclosporin A in patients. Biol Pharm Bull 24:683-687
Nakamura T, Sakaeda T, Horinouchi M, Tamura T, Aoyama N, Shirakawa T, Matsuo M, Kasuga M, Okumura K (2002) Effect of the mutation (C3435T) at exon 26 of the MDR1 gene on expression level of MDR1 messenger ribonucleic acid in duodenal enterocytes of healthy Japanese subjects. Clin Pharmacol Ther 71:297-303

Nashan B, Cole E, Levy G, Thervet E (2002) Clinical validation studies of Neoral $\mathrm{C}_{2}$ monitoring: a review. Transplantation 73:S3-S11

Nozu K, Iijima K, Sakaeda T, Okumura K, Nakanishi K, Yoshikawa N, Honda M, Ikeda M, Matsuo M (2005) Cyclosporin A absorption profiles in children with nephrotic syndrome. Pediatr Nephrol 20:910-913

Okamura N, Sakaeda T, Okumura K (2004) Pharmacogenomics of MDR and MRP subfamilies. Personalized Med 1:85-104

Pascussi JM, Gerbal-Chaloin S, Drocourt L, Maurel P, Vilarem MJ (2003) The expression of CYP2B6, CYP2C9 and CYP3A4 genes: a tangle of networks of nuclear and steroid receptors. Biochim Biophys Acta 1619:243-253

Ponticelli C (2005) Cyclosporine: from renal transplantation to autoimmune diseases. Ann N Y Acad Sci 1051:551-558

Sakaeda T, Nakamura T, Horinouchi M, Kakumoto M, Ohmoto N, Sakai T, Morita Y, Tamura T, Aoyama N, Hirai M, Kasuga M, Okumura K (2001) MDR1 genotyperelated pharmacokinetics of digoxin after single oral administration in healthy Japanese subjects. Pharm Res 18:1400-1404

Sakaeda T, Nakamura T, Okumura K (2003) Pharmacogenetics of MDR1 and its impact on the pharmacokinetics and pharmacodynamics of drugs. Pharmacogenomics 4:397-410

Sakaeda T, Nakamura T, Okumura K (2004) Pharmacogenetics of drug transporters and its impact on the pharmacotherapy. Curr Top Med Chem 4:1385-1398

Sakaeda T (2005) MDR1 genotype-related pharmacokinetics: fact or fiction? Drug Metab Pharmacokinet 20:391-414

Staudinger JL, Madan A, Carol KM, Parkinson A (2003) Regulation of drug transporter gene expression by nuclear receptors. Drug Metab Dispos 31:523-527

Thervet E, Pfeffer P, Scolari MP, Toselli L, Pallardo LM, Chadban S, Pilmore H, Connolly J, Buchler M, Schena FP, Carreno CA, Dandavino R, Cole E (2003) Clinical outcomes during the first three months posttransplant in renal allograft recipients managed by $\mathrm{C}_{2}$ monitoring of cyclosporine microemulsion. Transplantation 76:903-908

von Ahsen N, Richter M, Grupp C, Ringe B, Oellerich M, Armstrong VW (2001) No influence of the MDR-1 C3435T polymorphism or a CYP3A4 promoter polymorphism (CYP3A4-V allele) on dose-adjusted cyclosporin A trough concentrations or rejection incidence in stable renal transplant recipients. Clin Chem 47:1048-1052

Yates CR, Zhang W, Song P, Li S, Gaber AO, Kotb M, Honaker MR, Alloway RR, Meibohm B (2003) The effect of CYP3A5 and MDR1 polymorphic expression on cyclosporine oral disposition in renal transplant patients. J Clin Pharmacol 43:555-564

Wang H, LeCluyse EL (2003) Role of orphan nuclear receptors in the regulation of drug-metabolising enzymes. Clin Pharmacokinet 42:1331-1357

Wong SH (2001) Therapeutic drug monitoring for immunosuppressants. Clin Chim Acta 313:241-253 